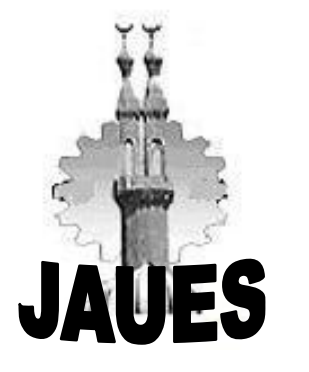

Journal of Al Azhar University Engineering Sector

Vol. 11, No. 38, January, 2016, 19-31

\title{
AN INNOVATIVE SHEAR WALLS COUPLING FOR ENHANCEMENT OF PERFORMANCE OF RC STRUCTURES
}

\author{
Dalia F. Arafa ${ }^{1}$, Hamed M. Salem², and Mohamed E. Issa ${ }^{2}$ \\ ${ }^{1}$ Concrete Structures Research Institute, Housing and Building Research Center, Egypt \\ ${ }^{2}$ Concrete Structures, Faculty of Engineering, Cairo University, Cairo, Egypt

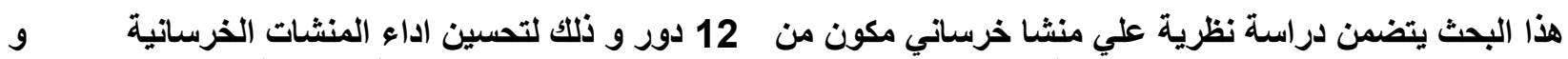

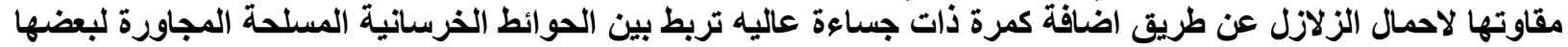

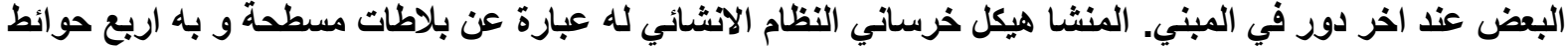

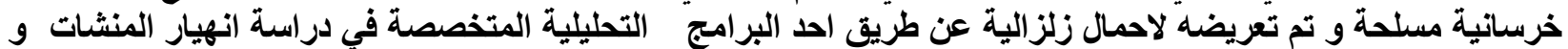

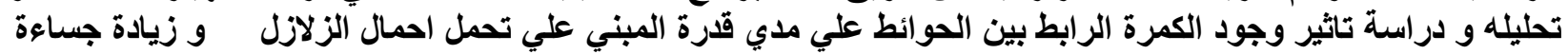
ABSTRACT

This research work numerically investigates an innovative shear walls coupling for enhancement of seismic performance of reinforced concrete structures. The new proposed technique links plane, relatively distant, shear walls with a top roof beam constituting framed-shear walls. The investigation is carried out for a twelve-floor reinforced concrete structure under the action of earthquake loading. The investigated structure has a flat slab-column construction system with four shear walls, $400 \mathrm{~mm} \times 3000 \mathrm{~mm}$ each, as the main lateral load resisting system. Each pair of aligned walls are connected at their top by a 6-meters long stiff beam. The top beam has the same width as the shear walls and different depths ranging from $500 \mathrm{~mm}$ to $3000 \mathrm{~mm}$. Analysis is carried out using the Applied Element Method. The Applied Element Method (AEM) is a discrete follows a discrete crack approach which was proven to track the structural collapse behavior passing through all stages of the application of loads. Behavior is evaluated in terms of the flexural moment redistribution in shear walls, the lateral load capacity increase of the walls, and the highest peak ground accelerations that the structure can withstand.

Keywords: Shear Walls; Stiffening Beam, variable depth and Dynamic Analysis

\section{INTRODUCTION}

The control of top drift and flexure in main lateral load resisting system in structures under lateral loads has become the main concern in the structural seismic design. The outrigger-braced system is regarded as one of the most effective ways of increasing structural stiffness and has been widely used. This was examined by several researchers. Fouad ${ }^{[1]}$ investigated the feasibility of using a top outrigger to stiffen a pair of coupled shear walls. The structure resisting lateral loads studied consisted of two-in plane walls connected by beams located at each floor level. The external columns located at the same walls plane contributed to the stiffness of the shear walls by placing a stiffening outrigger at the top of the walls. The outrigger and the peripheral columns resisted the walls rotation and reduced both moments and lateral drift. Ghan and Kuang ${ }^{[2]}$ presented an analytical method for investigating the beneficial effect of a stiffening beam on coupled shear walls internal forces and top deflection. The main variable was the location of the 
outrigger over the structural height. The application of a stiffening beam into coupled shear walls reduced the maximum shear force in the lintel beams and the base moment in the walls and the top drift of the structure. J.R.Wu and Q.S.Li ${ }^{[3]}$ presented a detailed analysis on the influence of variable outrigger locations and structural stiffness when a multi-level outrigger-braced tall building structure is subjected to uniformly distributed forces or triangularly distributed loads on the top drift, base moment in the core and the fundamental vibration period. The author concluded, that when the structure is subjected to horizontal triangular loads the optimum location of outrigger ranges between $4-5 \%$ compared to horizontal uniform loads. One of the most important deductions in this study, that the optimum location of outriggers is as near as possible to the foundation to reduce the base moment in the core. Bayati,Mahdikhani and Rahaei ${ }^{4]}$ presented the results of an investigation on drift reduction in uniform belted structures with rigid outriggers, through the analysis of a 80 story steel framed office. The proposed system consists of bracing at the walls of the 15 meters square core and three sets of outriggers located along the building height. Many benefits were offered by using the outrigger concept by the example demonstrated by the researchers such as, there are no trusses in the space between the core and the exterior columns. All exterior columns participate in resisting the overturning moments and the difficult connection between the truss and the core is eliminated. Wdowicki and Wdowicka ${ }^{[5]}$ investigated the non-planar asymmetric shear wall structures with stiffening deep beams located at various levels of coupled shear walls in tall buildings. The continuous connection method approach was used as a design tool for variable cross section coupled shear walls. In practice it was founded that the lintel beams on walls have limited depths, therefore it is necessary to insert deep beams somewhere along the height on the buildings. Numerical examples were presented to demonstrate the versatility and accuracy of the proposed technique. Kamath, Divya and Rao ${ }^{[6]}$ numerically inspected the behavior of different alternatives of 3D models with central core and a deep stiff beam connecting the central core to the most exterior columns. The height of the building has a major role in using these stiff beams, because when the height of the building increases, the core loses its adequate stiffness to keep the wind drift down to accepted limits. Two systems were analyzed through a dynamic analysis and compared, one with an outrigger and the second without. The model considered for analysis was a threedimensional 40 story building with $7 \mathrm{~m} \times 8 \mathrm{~m}$ central shear wall. It was concluded by the authors that the lateral displacement reduced about $37 \%$ by providing the outrigger the top and reduced up to $61 \%$ by providing outriggers at mid-height. The magnitude of the reduction in bending moments at base is of the order $95 \%$ by providing outriggers at mid-height of the core. The restraining movement of the columns to the outrigger system is the cause of this high reduction.

\section{RESEARCH SIGNIFICANCE}

In modern multistory buildings, lateral loads caused by wind and earthquake actions are often resisted by a system of shear walls located usually at sides of the building or in the form of a core which houses staircases or elevator shafts.

The current study aims to investigate the effect of locating a stiff beam connecting two plane, relatively distant, shear walls located at both sides of a twelve story structure together at the last floor on the seismic performance of the structure. The aim of locating such beam is to enhance the performance of midrise reinforced concrete structures to resist seismic forces and avoid the limited height and span to depth ratio restrictions of coupling beams. The use of such a top beam has also the architectural advantage of not affecting the building functionality. At one side, the shear walls need not to be very close to be couples. At the other side, there is no need to connect them at all floors, but only at roof. The case study is a 12 stories reinforced concrete structure with beamless slab floors. The structure has the plan dimensions of $24 \mathrm{~m}$ length $\mathrm{x} 18 \mathrm{~mm}$ width and consists of 4 bays each of $6 \mathrm{~m}$ width in the X-direction and 3 bays each of $3 \mathrm{~m}$ width in the Y-direction. The lateral load resisting system consists of 4 shear walls each 400x3000 $\mathrm{mm}$ and a stiff beam at the top of the structure connecting between each two pairs of shear walls. Six structures with different beam depths were analyzed under earthquake loading by applying artificial time-history acceleration records. 
Artificial ground motion records compatible with response spectrum were generated. Three timehistory records were generated from the SIMQKE_GR Version 2.6 Software ${ }^{[27]}$ following the Egyptian Code for Loads 201- 2012 requirements ${ }^{[7]}$. The analysis was carried out using the Extreme Loading of Structure (ELS) software. This Software depends on the Applied Element Method (AEM), which is a relatively new method, that is capable of predicting to a high degree of accuracy the continuum and discrete behavior of structures during a collapse situation. The Applied Element Method (AEM) was proven to be the method that can track the structural collapse behavior passing through all stages of the application of loads: elastic stage, crack initiation and propagation in tension-weak materials, reinforcement yielding, element separation, element collision (contact), and collision with the ground and with adjacent structures. The aim of the research was to study the effect of the stiffening beam located at top on the overall seismic behavior of the buildings.

\section{CASE STUDY}

3.1 Description of the Case Study Building

The full-scale building analyzed is shown in Fig. (1). The span of the stiff beam equal $6 \mathrm{~m}$ and has the same width as the shear wall and different depths ranging from $500 \mathrm{~mm}$ to $3000 \mathrm{~mm}$. Table (1) shows a geometrical description of each building and its notation.

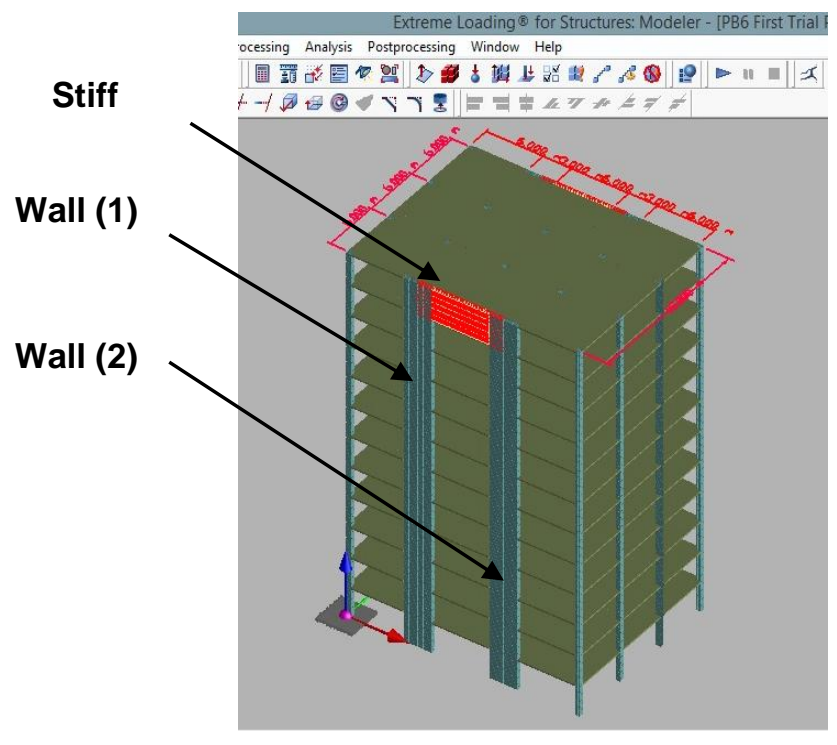

Fig.1: Full Scale Building Model in Extreme Loading Structures (ELS) Software

The prototype building studied is an office building and consists of 12 floors and is located in Cairo governorate. Its area is $18 \times 24 \mathrm{~m}^{2}$. The structural system is a slab-column construction. Slab thickness equals $150 \mathrm{~mm}$ and reinforced with a mesh of $6 \varnothing 12 / \mathrm{m}$ in both directions. The columns dimensions are 500x500 m and reinforced with $14 \varnothing 18$. Shear walls are $400 \mathrm{~mm}$ wide 3000 long and are reinforced with $15 \varnothing 22$ / each side. The connecting beam is $400 \mathrm{~mm}$ wide as the shear wall and the beam depth varied from $500 \mathrm{~mm}$ to $3000 \mathrm{~mm}$ with an increase in depth equal $50 \mathrm{~mm}$ in each building studied. Table (1) shows each building notation and its connecting beam dimensions. 
Table (1): Beam Dimensions in each Building

\begin{tabular}{|c|c|c|}
\hline Building Notation & $\begin{array}{c}\text { Beam Width b } \\
(\mathbf{m m})\end{array}$ & Beam Depth t (mm) \\
\hline PB0 & ---- & ----- \\
\hline PB1 & 40 & 50 \\
\hline PB2 & 40 & 100 \\
\hline PB3 & 40 & 150 \\
\hline PB4 & 40 & 200 \\
\hline PB5 & 40 & 250 \\
\hline PB6 & 40 & 300 \\
\hline
\end{tabular}

\section{APPLIED ELEMENT METHOD (AEM)}

The analysis was carried out using the Extreme Loading of Structure (ELS) software. This Software depends on the Applied Element Method (AEM), which is a new method, that is capable of predicting to a high degree of accuracy the continuum and discrete behavior of structures during a collapse situation. The Applied Element Method (AEM) was proven to be the method that can track the structural collapse behavior passing through all stages of the application of loads: elastic stage, crack initiation and propagation in tension-weak materials, reinforcement yielding, element separation, element collision (contact), and collision with the ground and with adjacent structures. Literature has shown that the Applied Element Method (AEM) theory gives good estimations for large displacements and deformations of structures undergoing collapse ${ }^{[8-26]}$. AEM is a modeling method adopting the concept of discrete cracking. As shown in Fig.(2), the structure in the AEM is modeled as an assembly of elements connected together along their surfaces through a set of normal and shear springs. The two elements shown in Fig. (2) are assumed to be connected by normal and shear springs located at the contact points, which are distributed on the element faces. These connecting springs represent the state of stresses, strains and connectivity between elements. They can represent both concrete and steel reinforcing bars.

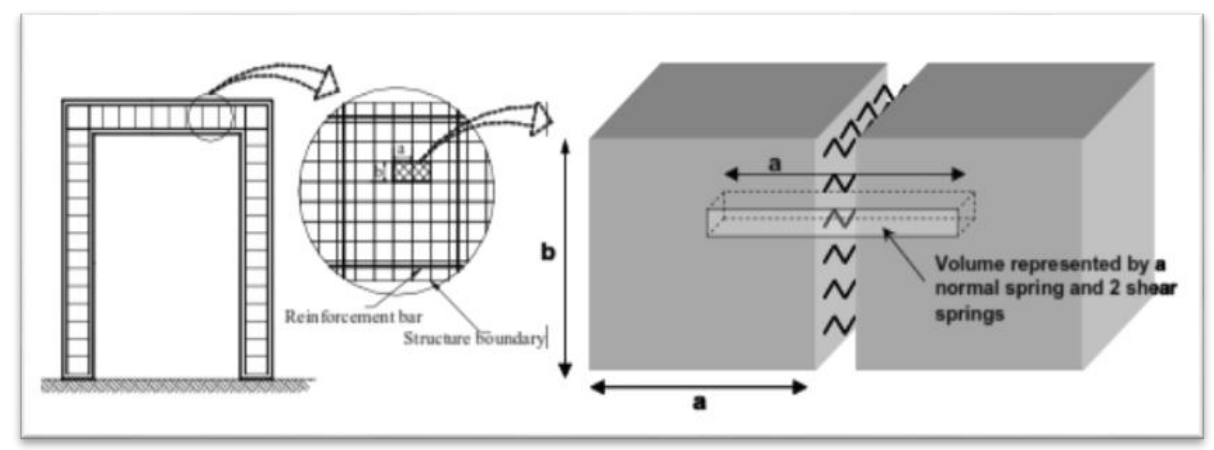

Fig. (2) Spring Distribution and Area of Influence of each pair of Springs

Each single element has six degrees of freedom: three for translations and three for rotations. Relative translational or rotational displacement between two neighboring elements cause stresses in the springs located at their common face. Two neighboring elements can be totally separated once the springs connecting them rupture.

\subsection{Material Models and Failure Criteria in ELS}

\subsubsection{Material Models}

Each reinforcement spring or matrix spring is assigned a specific material model. Each model has a set of parameters called the material properties. In the current version, three material models exist as follows. 


\section{a) Concrete Models in Compression}

Before and after cracking as for modeling of concrete under compression, the Maekawa Compression model ${ }^{[24]}$ as shown in Fig. (3-a) is adopted. In this model, three values are used to define the envelope for compressive stresses and compressive strains: the initial Young's modulus, the fracture parameter, representing the extent of the internal damage of concrete and the compressive plastic strain are introduced to define the envelope for compressive stresses and compressive strains. The tangent modulus is calculated according to the strain at the spring location. Unloading and reloading can be conveniently described in the model. After peak stresses, spring stiffness is assumed as a minimum value to avoid negative stiffness. This results in a difference between the calculated the stress and stress corresponding to the spring strain. These residual stresses are redistributed by applying the redistributed force value in the reverse direction in the next loading step. Figure (3) shows the constitutive models adopted in ELS. For concrete springs subjected to tension, spring stiffness is assumed as the initial stiffness until reaching the cracking point. After cracking, stiffness of springs subjected to tension is set to be zero. The residual stresses are then redistributed in the next loading step by applying the redistributed force values in the reverse direction. For concrete springs, the relationship between shear stress and shear strain is assumed to remain linear till the cracking of concrete. Then, the shear stresses drop down as shown in Fig. (3-b). The level of drop of shear stresses depends on the aggregate interlock and friction at the crack surface.

\section{b) Reinforcing Bars Model}

For reinforcement springs, the model presented by Ristic et al. ${ }^{[25]}$ is used and it is shown in Fig. (3-c). The tangent stiffness of reinforcement is calculated based on the strain from the reinforcement spring, loading status (either loading or unloading) and the previous history of steel spring which controls the Bauschinger's effect. The main advantage of this model is that it can consider easily the effects of partial unloading and Baushinger's effect without any additional complications to the analysis. The rupture strain of reinforcement is defined in ELS. For more details about material models used, refer to Tagel-Din and Meguro ${ }^{[26]}$.

\subsubsection{Failure Criterion}

\section{a) Cracking Criterion of Concrete}

The concrete is assumed to crack when the major principal stress reaches the tensile Strength of concrete. The 3D state of stresses at each spring location and the major

Principal stress is calculated as shown in Fig. (4) after cracking, there are mainly two ways to consider the crack if the crack is not coinciding on the element surface;

1 - To split the element into two elements and to generate new springs among the

Crack surface.

2- To leave the element as it is and to redistribute stresses resulting from cracking.

Both methods are shown in Fig. (5).

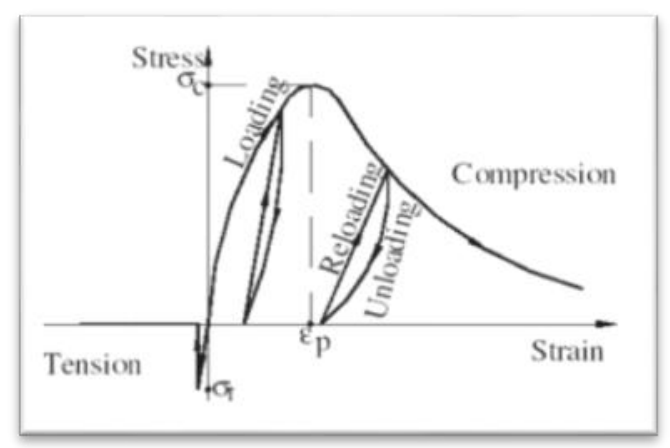

(a) concrete under axial stresses

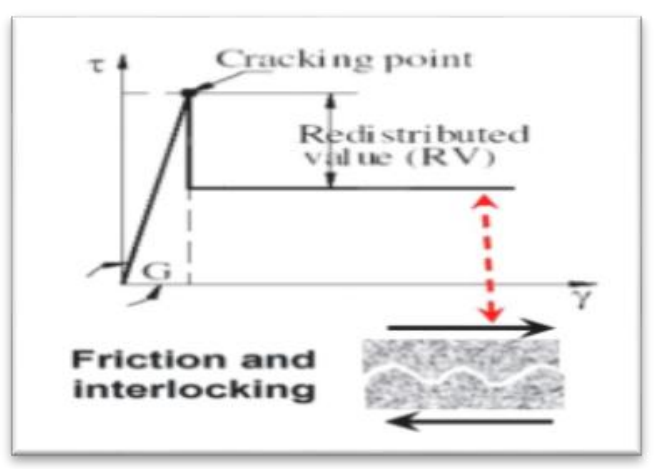

(b) concrete under shear stresses 


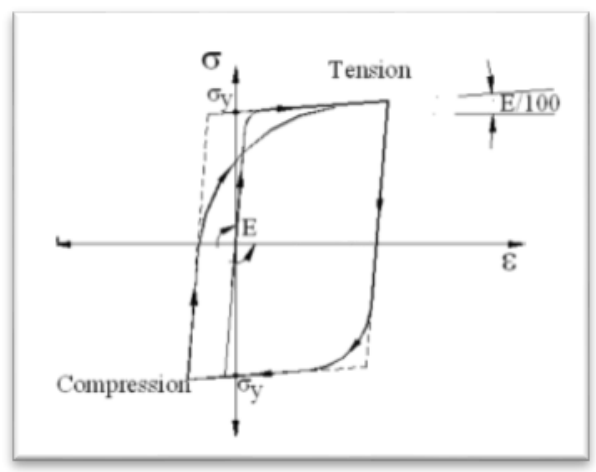

(c) Reinforcement under axial stresses

Fig. (3) Constitutive Models for Concrete and Reinforcement used in ELS

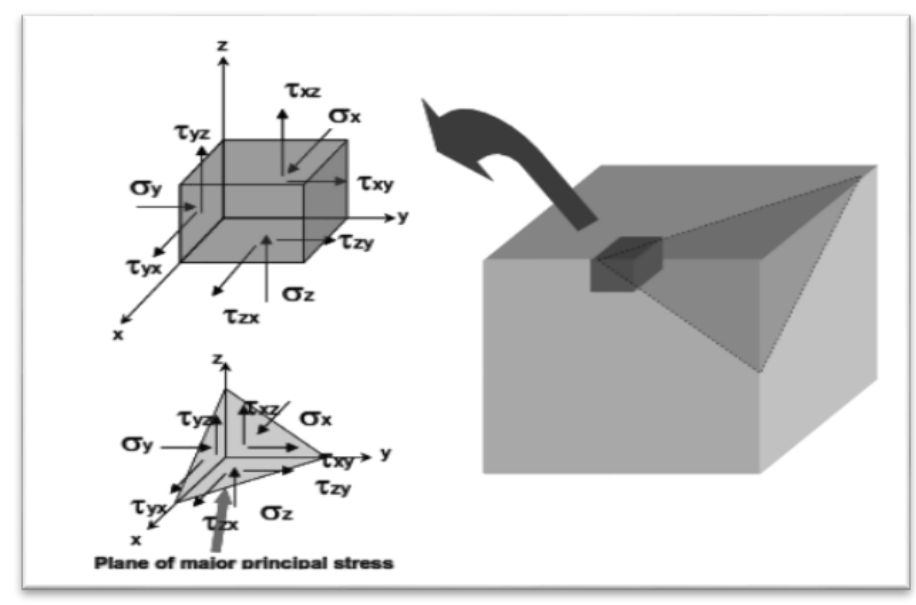

Fig. (4) Cracking Criterion of Concrete

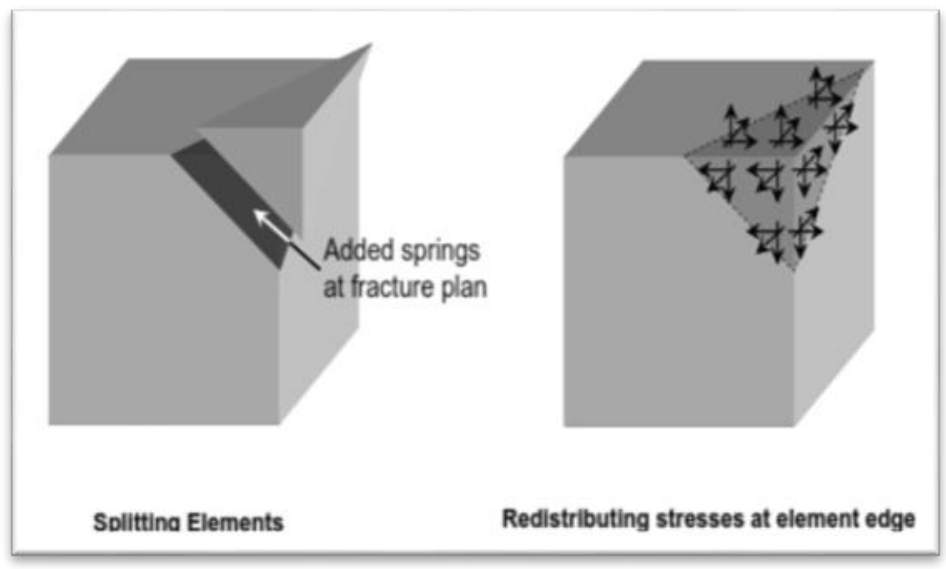

Fig. (5) Behavior of Concrete Elements after Cracking 


\section{DYNAMIC TIME - HISTORY ANALYSIS}

Three artificial Earthquake were generated using the SIMQKE_GR Version 2.6 Software ${ }^{[27]}$. The three artificial records showed close behavior and therefore the average upon the three was used in the analysis. The response spectrum for zone (3) Cairo Governorate was adopted based on the specifications of the Egyptian Code for Loads 201- 2012. ${ }^{[7]}$. The Time - History used for the dynamic analysis is shown in Fig. (4). The generated acceleration had a maximum acceleration of $1.47 \mathrm{~m} / \mathrm{sec}^{2}$ and a total duration of 20 seconds. A small-enough time step, equal 0.01 seconds, was used in the analysis to accurately follow the structural behavior.

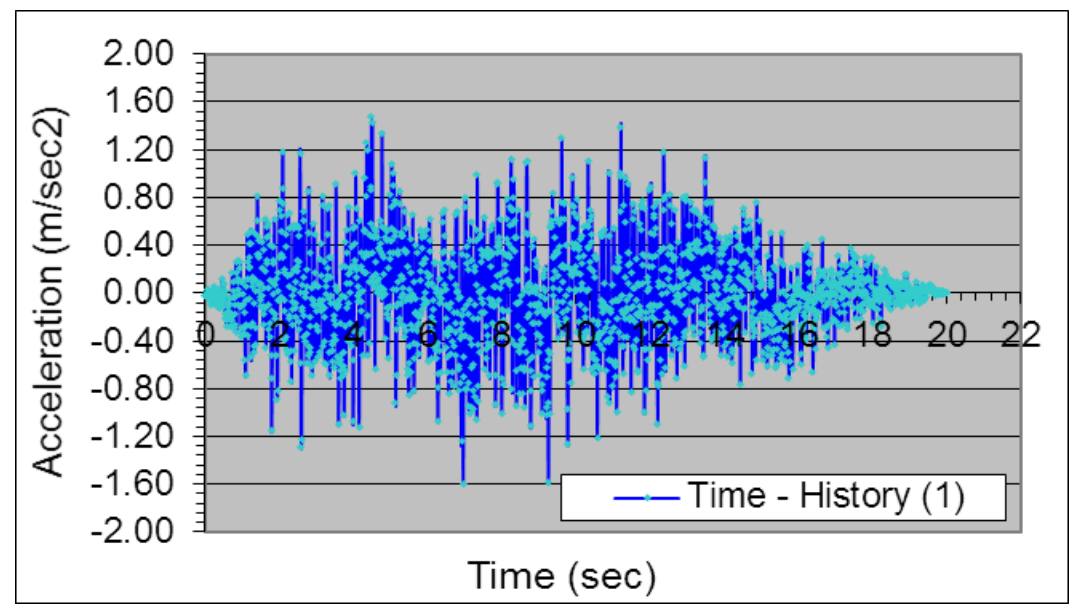

Fig. (4): Time - History Record

\subsection{DISCUSSION OF ANALYSIS RESULTS}

\subsubsection{Natural Period $(T)$}

The natural periods of the different structures in the current case study were obtained using the AEM. The predominant period, Mode 2 in x-direction, is shown in Table (2). As can be noticed, the use of the top beam results in reduction of the period of the structure. This is expected because of the increase in rigidity of the structure due to the use of the top beam. The higher the depth of the top beam, the higher the reduction in the period. The max reduction in natural period (T) occurred equal $12.00 \%$ for the case of PB6. Fig. (5) shows the periods corresponding to each Mode as obtained by the AEM ${ }^{[8-26]}$.

Table (2): Natural Period for studied structures

\begin{tabular}{|l|c|c|c|c|c|c|c|}
\hline Structure Notation & PB0 & PB1 & PB2 & PB3 & PB4 & PB5 & PB6 \\
\hline Natural Period (T) sec & 1.638 & 1.612 & 1.548 & 1.505 & 1.477 & 1.460 & 1.443 \\
\hline
\end{tabular}

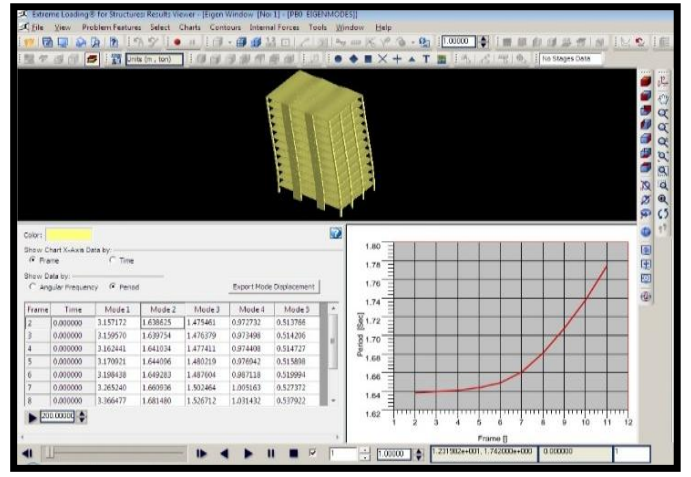

Fig. (5) Building PBO Natural Vibration Modes Analysis in ELS 


\subsubsection{Base Shear}

The time-base shear relation for different cases is shown in Fig. (6) for wall (1). The lateral load equaled the summation of all horizontal reactions at the structural base in the direction of earthquake (X-direction). Fig. (7) shows the increase obtained in the base shear due to the increase in stiffening beam depths. Due to the higher stiffness and the accompanied reduction in the structure period, for the same earthquake, the lateral load acting on the structure increases. The increase reached $44 \%$ for the case PB6 with top beam depth of $3000 \mathrm{~mm}$. In spite of that base shear increase, the analytical results showed that the structure withstood the applied earthquake. This is explained by its capacity increase as will be discussed later.
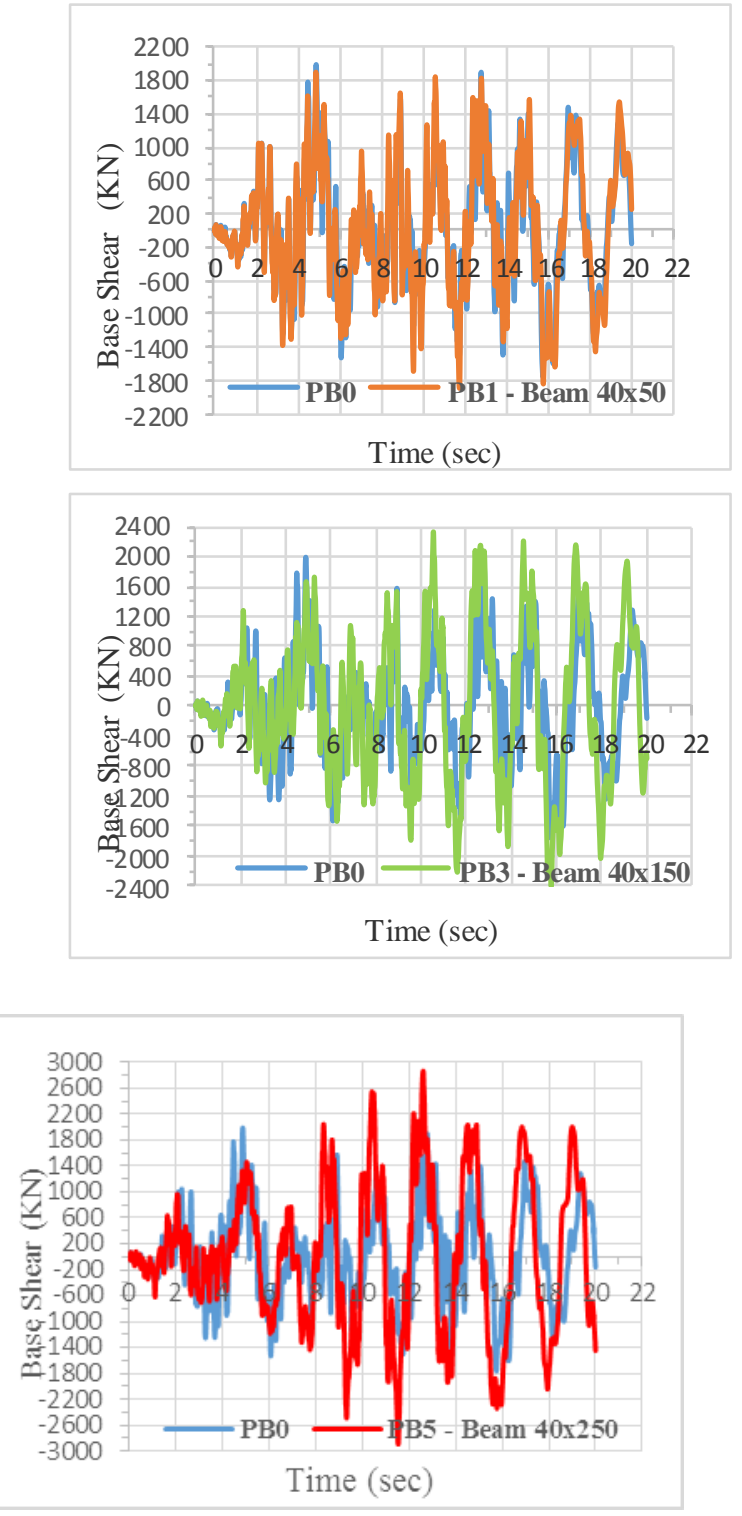
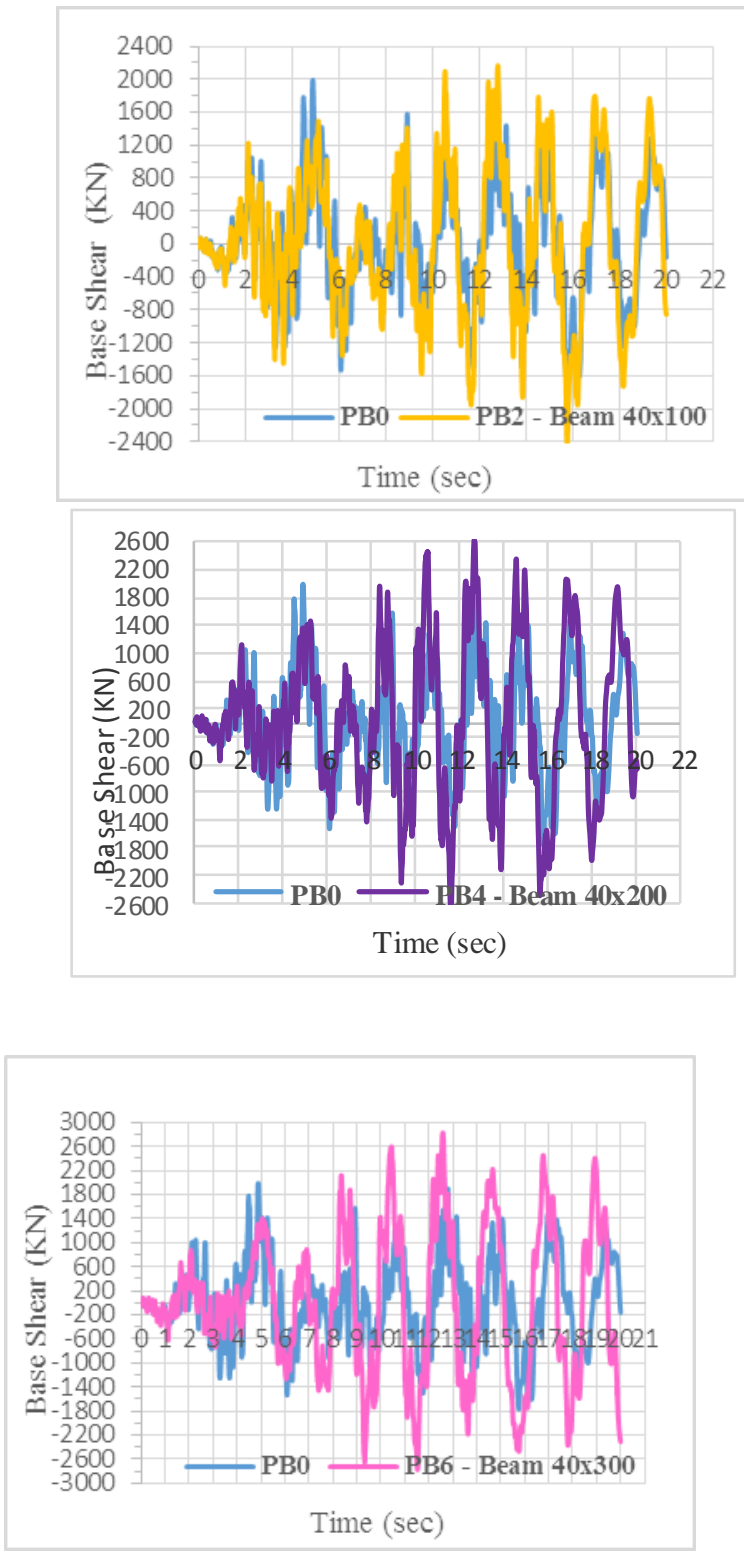

Fig. (6) Time - Base Shear Relations for Wall (1) 


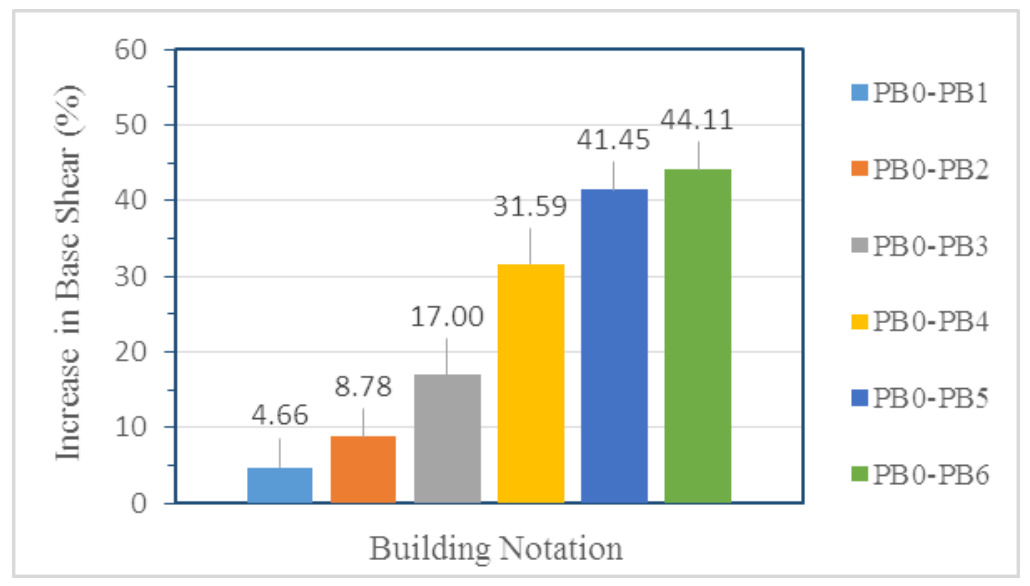

Fig. (7) Effect of top Beam rigidity on Base Shear

\subsubsection{Top Displacements}

The time-top displacement relation showed similar tendency as that of the base shear. Due to base shear increase, the top displacement values also increased as shown in Fig. (8). The lateral displacement at last floor reached its maximum value in case PB4 (Beam dimensions 400x2000 $\mathrm{mm}$ ) with an increase of $30.84 \%$ compared to the reference case.

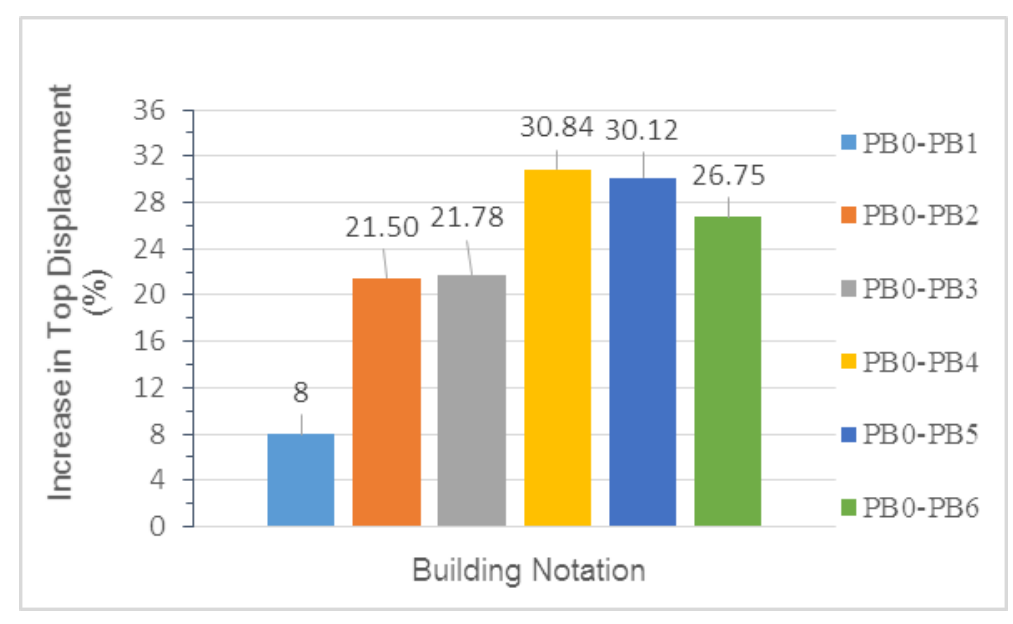

Fig. (8) Efficiency of proposed system in enhancing Top Displacement

\subsubsection{Moment Distribution in shear walls}

The new structural system proposed had an apparent effect on the moment distribution overall the wall height. The walls, which behave as cantilevers emerging from a fixed base will behave as two columns connected by a beam forming a frame. The walls can impose sufficient rotations on the connecting beam to make it yield and the beam if suitably detailed can be capable of dissipating energy over the entire height of the wall. In other words higher redundancy is introduced and hence higher strength is achieved. The moment values at each story, the moment envelope and moment distribution for each building can be seen in Fig. (9). 

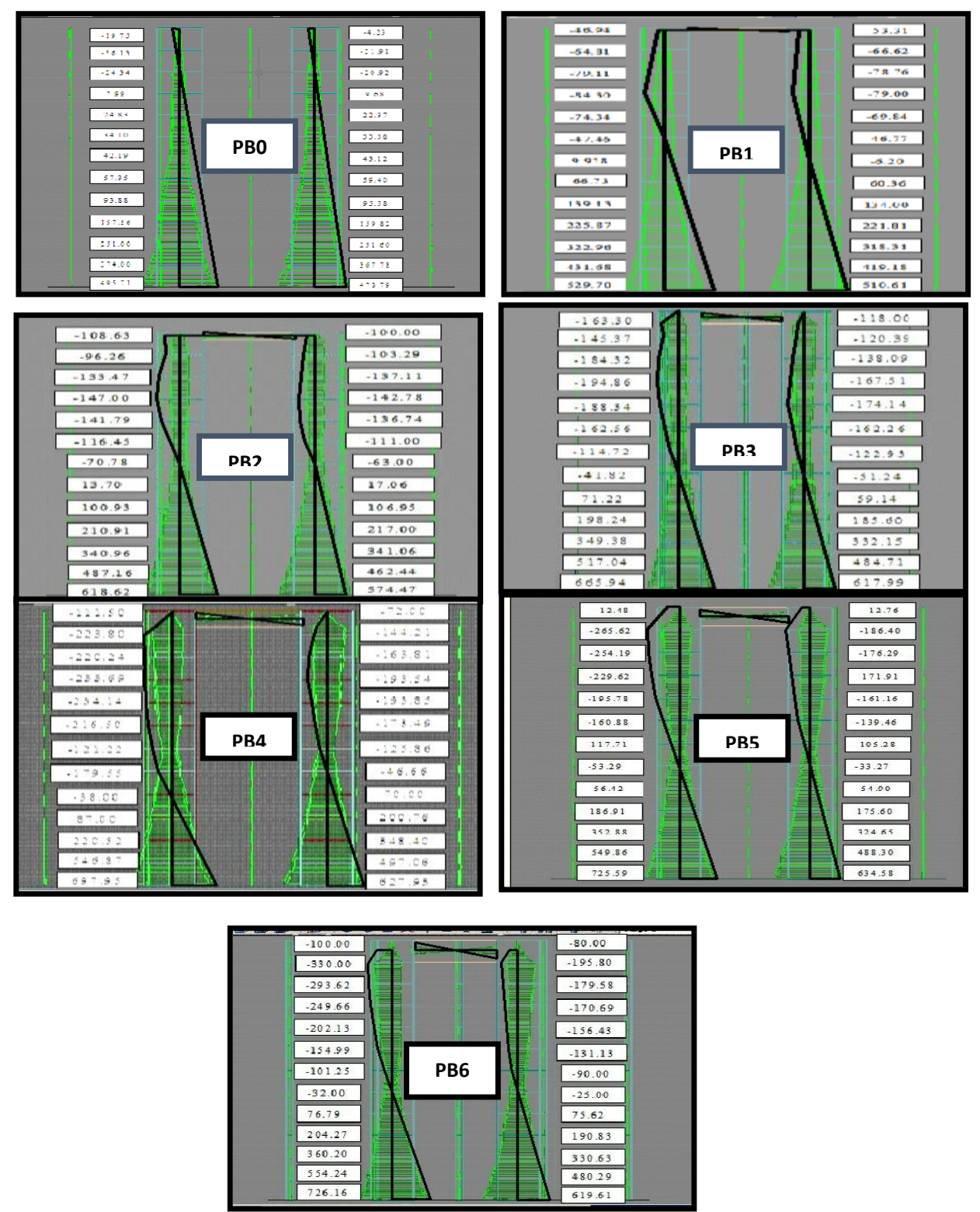

Fig. (9): Moment Distribution for all Buildings

The base moment is one of the main concerns in this research as the stiff beam plays an important role in changing the way the shear walls behave and thus the moment distribution. Fig. (10) shows the time-base moment relation for one shear wall (1), for case PB6 compared to case PB0. As shown, the base moment at the bottom of the shear wall increases with the increase in the top beam depth, explained by the increase in base shear. 

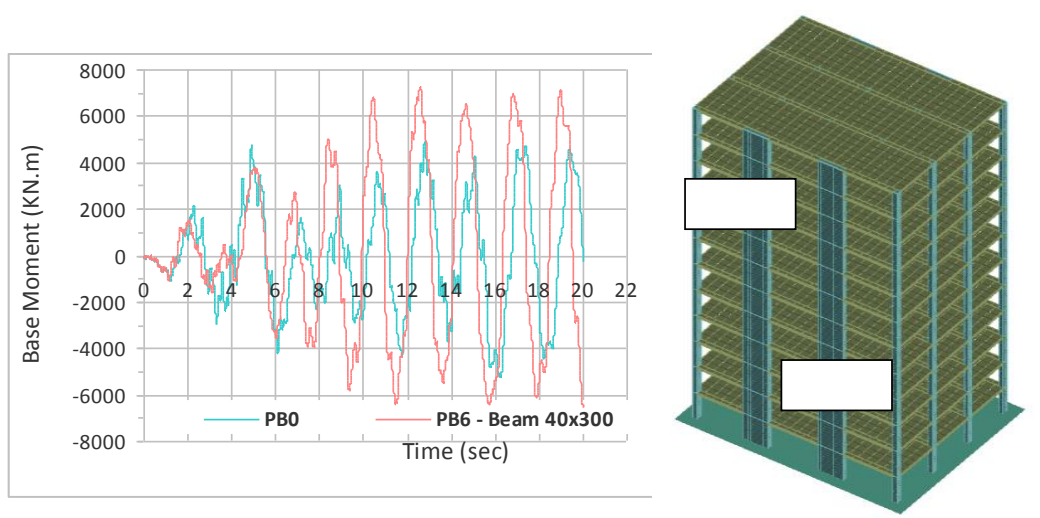

Fig.(10) Time - Base Moment Relation for Building PBo compared to Building PB6 for Wall (1)

Fig. (11) and (12) shows the raise in base bending moment values in shear walls. The highest increase was when the beam depth equaled the floor height $(48.34 \%)$.

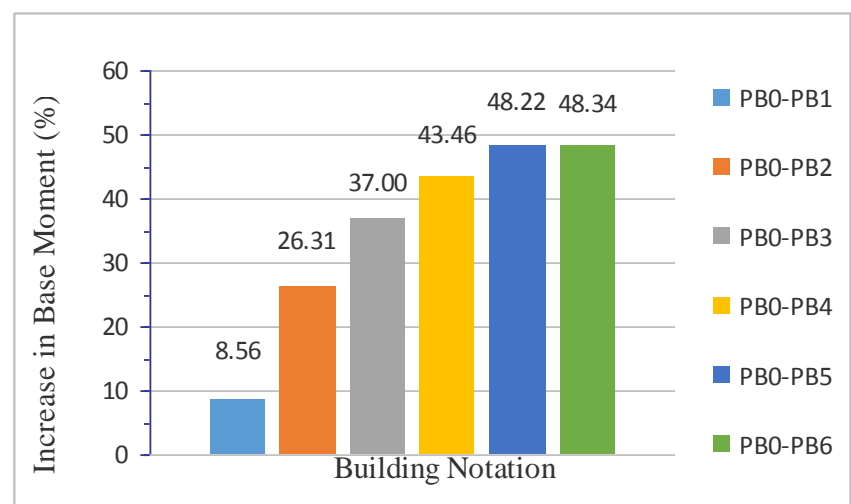

Fig. (11) Base Moment Capacity in Wall (1)

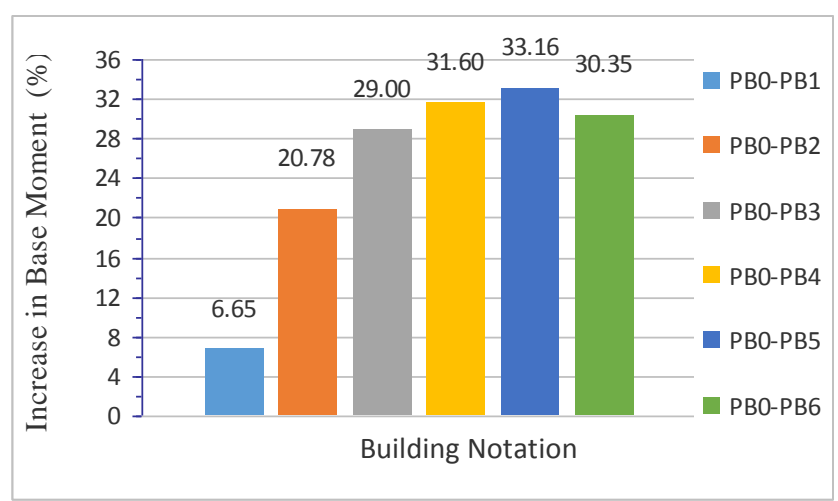

Fig. (12) Base Moment Capacity in Wall (2)

\section{CONCLUSIONS}

The current study investigates an innovative proposal for enhancing seismic resistance of reinforced concrete structures adopting shear walls as main lateral force resisting system. Based on a full nonlinear dynamic analysis of a twelve-story reinforced concrete building using the Applied Element Method, the following conclusions could be drawn: 
1- The addition of a top rigid beam that joins two distant shear walls is very useful in enhancing the capability of the building to resist higher lateral loads.

2- The top beam leads to transforming the shear wall behaviors from a cantilever to a framed-shear wall with higher rigidity. The connecting beam contributed in the resistance of the lateral loads acting on the building by redistributing the moments along the height of the shear walls.

3- The dynamic analysis confirmed the increase in the structural rigidity. A decrease in the natural period of $12.00 \%$ was obtained for the case of a rigid beam with $3.00 \mathrm{~m}$ depth. The base shear consecutively increased with a maximum value of $44 \%$ for the case of a rigid beam with $3.00 \mathrm{~m}$ depth.

\section{REFERENCES}

1- Fouad R.Moudarres, "Outrigger-Braced Coupled Shear Walls", (1984), ASCE Journal of Structural Engineering, Vol.110, No.12, pp.2877-2223.

2- H.C.Chan and J.S.Kuang, "Stiffened Coupled Shear Walls", April (1989), ASCE Journal of Engineering Mechanics, Vol.115, No.4, pp.689-702.

3- J.R.WU and Q.S.LI,"Structural Performance of Multi-Outrigger-Braced Tall Buildings", (2003), Structural Design of Tall and Special Buildings Journal, Vol.12, pp.155-176.

4- Z.Bayati,M.Mahdikhani and A.Rahaei, "Optimized Use of Multi-Outrigger System to stiffen Tall Buildings", (2008), 14 ${ }^{\text {th }}$ World Conference on Earthquake Engineering, October 12-17,Beijing,China.

5- Jacek Wdowicki and Elzbieta Wdowicka, "Analysis of non-planar shear wall structures with stiffening beams", (2011), CMM-Computer Methods in Mechanics, 9-12 May, Warsaw, Poland.

6- Kiran, Kamath ,N.Divya, Asha U Rao, "A Study on Static and Dynamic Behavior of Outrigger Structural System for Tall Buildings", (2012), Donfrig International Journal of Industrial Engineering and Management Science, Vol.2,No.4, December.

7- Egyptian Code of Practice for Loads 201, Egypt, 2012, p.125-126.

8- Galal K, El-Sawy T. Effect of retrofit strategies on mitigating progressive collapse of steel frame structures. Journal of Constructional Steel Research; 2010; 66 (4); 520-531.

9- Sasani M, Sagiroglu S. Progressive collapse resistance of hotel San Diego. Journal of Structural Engineering; 2008; 134(3); 478-488.

10- Salem H, El-Fouly A, Tagel-Din, H. Toward an economic design of reinforced concrete structures against progressive collapse. Engineering Structures; 2011; 33:.3341-3350.

11- Park H, Suk C, Kim S. Collapse modeling of model RC structures using the applied element method. Journal of Korean Society for Roc Mechanics, Tunnel\& Underground Space; 2009; 19 (1); 43-51.

12- Helmy H, Salem H, Tageldin H. Numerical simulation of Charlotte Coliseum demolition using the applied element method. USNCCM-10 conference-Ohio-USA; 2009.

13- Sasani M. Response of a reinforced concrete infilled-frame structure to removal of two adjacent columns. Engineering Structures; 2008; 30, 2478-2491.

14- Wibowo H, Reshotkina S, Lau D. Modelling progressive collapse of RC bridges during earthquakes, CSCE Annual General Conference; 2009; GC-176-1-11.

15- Tagel-Din H, Rahman N. Extreme loading: breaks through finite element barriers. Struct Eng 2004; 5(6); 32-40.

16- Salem H. Computer-aided design of framed reinforced concrete structures subjected to flood scouring. Journal of American Science; 2011; 7(10); 191-200.

17- ASCE/SEI 7-05, Minimum design loads for buildings and other structures. NY: American Society of Civil Engineers, 2005.

18- D. Asprone, A. Nanni, H. Salem, and H. Tagel-Din: Applied Element Method Analysis of Porous GFRP Barrier Subjected to Blast, Advances in Structural Engineering, Vol. 13, No. 1, 153-169, 2010 
19- Helmy H., Salem H. , and Mourad S. "Progressive collapse assessment of framed reinforced concrete structures according to UFC guidelines for alternative path method", Engineering Structures 42 (2012) 127-141

20- Helmy, H., Salem, H., and Mourad, S.. "Computer-Aided Assessment of Progressive Collapse of Reinforced Concrete Structures according to GSA Code." J. Perform. Constr. Facil., 27(5), (2013), 529-539.

21-Salem, H. and Helmy, H. "Numerical investigation of collapse of the Minnesota I-35W bridge" Engineering Structures, Volume 59, (February 2014), 635-645

22-Salem, H., Mohssen, S., Kosa, K. and Hosoda, A. "Collapse Analysis of Utatsu Ohashi Bridge Damaged by Tohuku Tsunami using Applied Element Method", Journal of Advanced Concrete Technology, Volume 12, (October 2014), 388-402

23-Ehab, M., Salem, H., Mostafa, H., and Yehia, N. "Earthquake Pounding Effect on Adjacent Reinforced Concrete Buildings" International Journal of Computer Applications, Volume 106, No.9,( November 2014), 0975 - 8887

24- Okamura H. and Maekawa K.: Nonlinear analysis constitutive models of reinforced concrete, Gihodo Co. Ltd., Tokyo, 1991.

25- Ristic,D.,Yamada,Y., and Iemura,H.(1986), "Stress-strain based modeling of hysteretic structures under earthquake induced bending and varying axial loads", Research report No. 86-ST-01, School of Civil Engineering, Kyoto University, Kyoto, Japan.

26- Hatem Tagel-Din and Kimiro Meguro: Applied Element Method for Dynamic Large Deformation Analysis of Structures, Structural Eng./Earthquake Eng., International Journal of the Japan Society of Civil Engineers (JSCE), Vol. 17, No. 2, pp. 215s-224s, October 2000.

27-SIMQKE_GR Version 2.6 by Prof.Piero Gelfi, University of Brescia (Italy), April 2011. 